\title{
Epidemiological characteristics of children with autoimmune thyroid disease
}

\author{
Vasiliki Skarpa, ${ }^{1}$ Eleni Kousta, ${ }^{1}$ Athanasia Tertipi, ${ }^{1}$ Konstantinos Anyfandakis, ${ }^{1}$ \\ Marina Vakaki, ${ }^{2}$ Maria Dolianiti, ${ }^{1}$ Aspasia Fotinou, ${ }^{3}$ Asteroula Papathanasiou ${ }^{1}$
}

${ }^{1}$ Department of Pediatric Endocrinology, ${ }^{2}$ Department of Radiology, ${ }^{3}$ Department of Microbiology, 'P. \& A. Kyriakou' Children's Hospital, Thivon \& Levadias Str, Athens 11527, Greece

\begin{abstract}
OBSECTIVE: Chronic autoimmune thyroiditis (AT) is the most common cause of thyroid disease in children. The aim of the study was to define the epidemiological clinical and laboratory characteristics of children and adolescents with AT. DESIGN: Various parameters including thyroid ultrasonography of 228 children and adolescents aged $10.2 \pm 2.5 y r s($ mean \pm SD) with AT, who attended our Pediatric Endocrine Unit during a 5-year period were retrospectively analysed. RESULTS: 191 (83.8\%) were female and 142 (62.3\%) were pubertal. At AT diagnosis, 130 children $(57.0 \%)$ were euthyroid, 75 (32.9\%) had subclinical hypothyroidism, $19(8.3 \%)$ had hypothyroidism and $4(\mathbf{1 . 8 \%})$ had hyperthyroidism. There was a positive correlation between thyroid stimulating hormone (TSH) levels and thyroid volume SDS $(r=0.15, p=0.02)$. Sixtythree children $(28 \%)$ had a goiter and $32(14 \%)$ had thyroid nodules. Three children $(1.3 \%)$ had papillary thyroid carcinoma. Compared to euthyroid children, children with hypothyroidism were younger $(9.2 \pm 1.8$ vs $10.6 \pm 2.4 y r s, p<0.05)$ and had higher thyroid volume SDS $(3.1 \pm 1.9$ vs $1.2 \pm 1.2, p<0.05)$ and higher prevalence of goiter $[11(57.9 \%)$ vs $29(22.3 \%), p<0.05]$. CONCLUSIONS: Children and adolescents with AT are mostly asymptomatic; the majority are female, pubertal and euthyroid. Hypothyroid children with AT have higher thyroid volume, higher prevalence of goiter and higher antithyroid antibodies titers compared to euthyroid children. Diagnosing AT at an early stage offers the opportunity for a timely intervention. The potential association of AT with papillary thyroid carcinoma is an additional reason for a careful follow-up of the patients with AT.
\end{abstract}

Key words: Autoimmune thyroiditis, Hashimoto thyroiditis, Goiter, Thyroid ultrasonography, Thyroid nodules, Thyroid cancer

Address for correspondence:

Dr Eleni Kousta, 6, S. Arvanitaki street, Corfu 49100, Greece, Tel.: +30 26610 80561, Fax: +302661080562, e-mail: lkousta@otenet.gr

Received 25-03-11, Revised 24-05-11, Accepted 10-06-11

\section{INTRODUCTION}

Chronic autoimmune thyroiditis (AT) is characterised by the presence of thyroid autoantibodies in serum and has a varying prevalence according to the 
criteria used for diagnosis, the ethnicity, the iodine status, the age and the gender; ${ }^{1}$ it has been reported that approximately $10-13 \%$ of most populations have positive thyroglobulin autoantibodies ( $\mathrm{TgAb}$ ) or thyroid peroxidase (TPO) autoantibodies. ${ }^{2-6}$ AT is the most common cause of thyroid disorder among children and adolescents and has a wide spectrum of clinical manifestations and a variable clinical course. ${ }^{6-13}$ Among Greek children, the prevalence of positive thyroid autoantibodies is estimated to be between $4-10 \%$, the prevalence of goiter $3.2 \%$, the prevalence of thyroid nodules $5.1 \%$ and the prevalence of altered thyroid echostructure approximately $9 \% .{ }^{14-16}$ Studies assessing iodine status among Greek schoolchildren have shown iodine sufficiency. ${ }^{14,15}$ Almost one decade after the elimination of iodine deficiency in Greece, there has been an increase in the prevalence of autoimmune thyroiditis. ${ }^{11}$ The epidemiological and clinical characteristics of AT among children differ widely in the various studies. ${ }^{6,717-20}$

The aim of the present study was to analyse retrospectively the epidemiological, clinical and laboratory characteristics of children and adolescents with AT attending a large Pediatric Endocrinology Unit in Athens, Greece. We assessed 228 children and adolescents with AT using, in addition to clinical and laboratory parameters, thyroid ultrasonography.

\section{SUBJECTS AND METHODS}

Between January 2001 and December 2005, 228 children with AT attended the outpatient pediatric endocrinology clinic of our hospital and entered the AT database. Inclusion criteria were positivity for at least one of the antithyroid antibodies [thyroglobulin (anti-TgAb) or TPO autoantibodies (anti-TPOAb)] and hypoechogenicity on thyroid ultrasound scan. Among these children, 29 had been diagnosed as having AT between 1996 and 2000 and were followed up between 2001-2005, 19 were diagnosed as having AT in the year 2001, 37 in the year 2002, 28 in the year 2003, 56 in the year 2004 and 59 in the year 2005.

Groups with a high prevalence of AT, such as children with Turner syndrome, Down syndrome (trisomy 21) and type 1 diabetes, were excluded from the study. Children with Graves' disease and children with secondary causes of thyroid dysfunction, such as those who had undergone cervical radiotherapy for cancer, were also excluded. Children who dropped out of the clinic before investigations were completed were not included in the database.

The main reasons for referral of these children were investigation of growth $(\mathrm{n}=52(23 \%)$ or thyroid enlargement $(\mathrm{n}=42(18 \%)$ and/or a family history of thyroid disease $(n=39(17 \%)$ (Table 1$)$.

Assessment involved personal and family history for thyroid disease and other autoimmune diseases, anthropometry [height, weight, body mass index (BMI) and pubertal status], thyroid function tests and thyroid ultrasound scan. Pubertal status was assessed using Tanner staging. The study was approved by the faculty of medicine Athens Medical School.

Free triiodothyronine (FT3), free thyroxin (FT4) and thyroid stimulating hormone (TSH) were measured by electrochemiluminescence immunoassay (ECLIA) (Roche Diagnostics, Elecsys 2010 immunoassay analyzer). During the study period the method of detecting thyroid autoantibodies in our laboratory was changed. Until 2002 the method of measuring Anti-TPOAb and anti-TgAb was by the passive haemmaglutination test being characterized as positive or negative. Subsequently, thyroid autoantibodies were measured by chemiluminescence (Nichols Institute Diagnostics, San Juan Capistrano, USA), the normal values being for anti-TPOAb $<2 \mathrm{IU} / \mathrm{ml}$ and for anti$\mathrm{TgAb}<1 \mathrm{IU} / \mathrm{ml}$. Since the method of detecting thyroid autoantibodies changed in our laboratory during the study period, we have not been able to accurately assess

Table 1. Reasons for referral of children with autoimmune thyroid disease to our Pediatric Endocrine Clinic

\begin{tabular}{lcc}
\hline & n & $(\boldsymbol{\%})$ \\
\hline Investigation of growth & 52 & $(23)$ \\
Thyroid enlargement & 42 & $(18)$ \\
Family history of thyroid disease & 39 & $(17)$ \\
Obesity & 22 & $(10)$ \\
Abnormal thyroid function tests or positive & 20 & $(9)$ \\
thyroid autoantibodies on a routine check-up & & \\
High cholesterol values & 11 & $(5)$ \\
$\begin{array}{l}\text { Various signs or symptoms like tachycardia, } \\
\text { bradycardia, alopecia, vitiligo }\end{array}$ & 42 & $(18)$ \\
\hline
\end{tabular}


differences in the degree of positivity. We, however, arbitrarily considered as strongly positive antibody titres 10 times above the normal range.

The children were classified as subclinical hypothyroid if they had elevated serum TSH (normal range $0.4-5 \mathrm{mIU} / \mathrm{ml}$ ), normal serum FT3 (normal range $2.40-5.00 \mathrm{pg} / \mathrm{ml}$ ) and FT4 (normal range 0.80-2.00 $\mathrm{ng} / \mathrm{dl}$ ) and as hypothyroid if they had elevated serum TSH and low serum FT4.

\section{Thyroid ultrasound}

Thyroid volume and morphology were determined by two experienced ultrasonographers (M.V. and C.K.) of our Hospital using a high-resolution ultrasound scan (Phillips HDI 3000 ATL, Bothell, WA, USA), equipped with a 5-10 MHz linear-array probe. Examinations were performed in a supine position with the neck hyperextended. The length (1), width (w) and depth (d) of each thyroid lobe (in centimetres) were measured on transverse and longitudinal scans. The volume of each thyroid lobe (in millilitres) was estimated by the modified formula of the rotation ellipsoid, $\operatorname{Vol}(\mathrm{ml})=0.479 \times \mathrm{d} \times \mathrm{w} \times 1$. The thyroid volume was defined as the sum of the volumes of both lobes, without including the isthmus. ${ }^{21}$ For assessment of thyroid volume SDS, the following formula was used: thyroid volume SDS = measured volume-mean predicted volume for age and sex/SD. ${ }^{15}$ Patients were considered to be goitrous if they had a thyroid volume SDS greater than 2.0.

The ultrasonographic diagnosis of hypoechogenicity was carried out by subjectively assessing the thyroid echogenicity in reference to the strap muscle of the neck. ${ }^{22}$ The presence of nodules $(>0.5 \mathrm{~cm}$ in size) was also recorded. A fine needle aspiration (FNA) was performed in all children who had a nodule diameter $\geq 1 \mathrm{~cm}$.

\section{Statistics}

Data are presented as mean \pm SD. Statistical analyses were performed using SPSS 11.0 for Windows, using the student's t- test for comparison between two groups, ANOVA to compare means between 3 groups, the $\chi^{2}$ test ( $\mathrm{r} x \mathrm{c}$ contingency table) to analyse quantitative values and the Pearson correlation test to measure the proximity of the association of two variables.

\section{RESULTS}

Patients' characteristics at diagnosis of AT are shown in Table 2. Among the 228 children, 122 $(53.5 \%)$ had strongly positive anti-TPOAb, 91 (39.9\%) had strongly positive anti-TgAb and $62(27.2 \%)$ had strongly positive anti-TPOAb and anti-TgAb. Thyroid volume in the whole group was $7.9 \pm 4.0 \mathrm{ml}$ and thyroid volume SDS was $1.4 \pm 1.5$. There was a positive correlation between TSH levels and thyroid volume SDS $(r=0.15, p=0.02)$. Sixty-three children $(28 \%)$ had goiter. Thyroid nodules were present in 32 $(14 \%)$ children with AT (15 of whom had a goiter); 13 of them had nodules $\geq 1 \mathrm{~cm}$ and underwent FNA.

Table 2. Characteristics of the 228 children at the time of diagnosis of autoimmune thyroiditis (AT)

\begin{tabular}{|c|c|}
\hline $\begin{array}{l}\text { Gender } \mathrm{n}(\%) \\
\text { female } \\
\text { male }\end{array}$ & $\begin{array}{l}191(83.8) \\
37(16.2)\end{array}$ \\
\hline $\begin{array}{l}\text { Pubertal status n (\%) } \\
\text { - prepubertal (Tanner I) } \\
\text { - pubertal (Tanner II-IV) }\end{array}$ & $\begin{array}{l}86(37.7) \\
142(62.3)\end{array}$ \\
\hline Age in years $($ mean $\pm S D)$ & $10.2 \pm 2.5$ (range $3.3-15.3)$ \\
\hline $\begin{array}{l}\text { Ethnicity } \\
\text { Greek } \\
\text { Albanian } \\
\text { German }\end{array}$ & $\begin{array}{c}218 \\
9 \\
1\end{array}$ \\
\hline $\begin{array}{l}\text { Autoimmune disease other than } \\
\text { AT n }(\%) \\
\text { rheumatoid arthritis: } \\
\text { vitiligo: } \\
\text { alopecia: }\end{array}$ & $\begin{array}{c}6 \text { (5 girls, } 1 \text { boy }) \\
7 \text { girls } \\
2 \text { girls }\end{array}$ \\
\hline $\begin{array}{l}\text { Family history of thyroid disease } \\
\text { in a first degree relative } \mathrm{n}(\%)\end{array}$ & $174(76.3)$ \\
\hline $\begin{array}{l}\text { Family history of autoimmune } \\
\text { disease other than AT in a first } \\
\text { degree relative } n(\%)\end{array}$ & $20(8.8)$ \\
\hline $\begin{array}{l}\text { Thyroid hormone status n }(\%) \\
\text { euthyroid: } \\
\text { subclinical hypothyroidism: } \\
\text { hypothyroidism: } \\
\text { hyperthyroidism (Hashitoxicosis): }\end{array}$ & $\begin{array}{l}130(57.0) \\
75(32.9) \\
19(8.3) \\
4(1.8)\end{array}$ \\
\hline *Goiter n (\%) & $63(28)$ \\
\hline *Thyroid nodules n (\%) & $32(14)$ \\
\hline
\end{tabular}

*The prevalence of goiter and thyroid nodules in the general pediatric population in the same geographic region is 3.2 and $5.1 \%$, respectively. ${ }^{15}$ 
Three of these children (1.3\% of children with AT) who were diagnosed by FNA as having papillary thyroid cancer underwent thyroidectomy and histology confirmed the presence of papillary thyroid cancer.

The characteristics of the studied subjects according to the thyroid function status are shown in Table 3. Age was significantly different between groups (Table 3 ) children with hypothyroidism were almost one year younger than euthyroid children $(p<0.05)$. Pubertal status was significantly different between groups. The majority of euthyroid children were pubertal, whereas the majority of children with hypothyroidism were prepubertal $(\mathrm{p}<0.05)$. Thyroid volume, thyroid volume SDS and the prevalence of goiter were significantly different between the three groups; all these parameters were higher in children with hypothyroidism compared to euthyroid children $(\mathrm{p}<0.05)$. There was no difference in the prevalence of thyroid nodules, gender distribution, height SDS, BMI SDS, prevalence of an autoimmune disease other than AT, prevalence of family history of thyroid disease in a first degree relative and prevalence of an autoimmune disease other than AT in a first degree relative between the three groups. The prevalence of thyroid dysfunction did not differ by reason of referral.

Children with hypothyroidism $(\mathrm{n}=19)$ compared to euthyroid and subclinical hypothyroid children $(n=205)$ had significantly higher prevalence of strongly positive anti-TPOAb [17 (89.5\%) vs 102 (49.8\%), $\left.\left.\chi^{2}=11.02, p=0.0009\right)\right]$ and of strongly positive both anti-TPOAb and anti-TgAb [9 (47.4\%) vrs 51 (24.9\%), $\left.\chi^{2}=4.48, \mathrm{p}=0.003\right]$. There was no significant difference in the prevalence of strongly positive anti- $\mathrm{TgAb}$ between the two groups euthyroid $v s$ subclinical hypothyroid $\left[10(52.6 \%)\right.$ and $79(38.5 \%), \chi^{2}=1.44$, respectively, $\mathrm{p}=0.23$.

\section{DISCUSSION}

This is a retrospective study aiming to investigate

Table 3. Characteristics of euthyroid, subclinically hypothyroid and hypothyroid children with AT, at diagnosis. The 4 children with hyperthyroidism are not included in this analysis. NS: non significant

\begin{tabular}{|c|c|c|c|c|}
\hline & $\begin{array}{c}\text { Euthyroid } \\
(n=130)\end{array}$ & $\begin{array}{c}\text { Subclinical } \\
\text { hypothyroidism } \\
(\mathbf{n}=75)\end{array}$ & $\begin{array}{l}\text { Hypothyroidism } \\
(n=19)\end{array}$ & $\begin{array}{c}p \text { value for } \\
\text { comparison } \\
\text { between groups }\end{array}$ \\
\hline Age in years (mean $\pm S D)$ & $10.6 \pm 2.4$ & $10.2 \pm 2.5$ & $9.2 \pm 1.8$ & $<0.05$ \\
\hline $\begin{array}{l}\text { Gender } \\
\quad \text { - female } \mathrm{n}(\%) \\
\text { - male n }(\%)\end{array}$ & $\begin{array}{l}109(83.8) \\
21(16.2)\end{array}$ & $\begin{array}{l}64(85.3) \\
11(14.7)\end{array}$ & $\begin{array}{l}15(78.9) \\
4(21.1)\end{array}$ & NS \\
\hline Height SDS (mean \pm SD) & $0.9 \pm 1.2$ & $0.6 \pm 1.3$ & $1.5 \pm 1.0$ & NS \\
\hline BMI SDS (mean \pm SD) & $0.9 \pm 1.1$ & $0.9 \pm 1.3$ & $0.3 \pm 1.3$ & NS \\
\hline $\begin{array}{l}\text { Pubertal status } \\
\text { - prepubertal n (\%) } \\
\text { - pubertal n }(\%)\end{array}$ & $\begin{array}{l}39(30.0) \\
91(70.0)\end{array}$ & $\begin{array}{l}34(45.3) \\
41(54.7)\end{array}$ & $\begin{array}{l}12(63.2) \\
7(36.8)\end{array}$ & $<0.01$ \\
\hline Autoimmune disease other than AT n (\%) & $11(8.5)$ & $4(5.3)$ & $0(0)$ & NS \\
\hline $\begin{array}{l}\text { Family history of thyroid disease in a first degree relative } \\
\mathrm{n}(\%)\end{array}$ & $97(74.6)$ & $59(78.7)$ & $15(78.9)$ & NS \\
\hline $\begin{array}{l}\text { Family history of autoimmune disease other than AT in } \\
\text { a first degree relative } \mathrm{n}(\%)\end{array}$ & $11(8.5)$ & $6(8.0)$ & $2(10.5)$ & NS \\
\hline TSH (IU/L) (mean \pm SD) & $2.7 \pm 1.1$ & $7.8 \pm 3.2$ & $55.2 \pm 34.0$ & $<0.01$ \\
\hline Thyroid volume in $\mathrm{ml}($ mean $\pm \mathrm{SD})$ & $7.6 \pm 3.4$ & $7.5 \pm 3.8$ & $12.3 \pm 5.7$ & $<0.01$ \\
\hline Thyroid volume SDS (mean \pm SD) & $1.2 \pm 1.2$ & $1.3 \pm 1.5$ & $3.1 \pm 1.9$ & $<0.01$ \\
\hline *Goiter n (\%) & $29(22.3)$ & $22(31.5)$ & $11(57.9)$ & $<0.01$ \\
\hline *Nodules n (\%) & $17(13.1)$ & $11(14.7)$ & $3(15.8)$ & NS \\
\hline
\end{tabular}

*The prevalence of goiter and thyroid nodules in the general pediatric population in the same geographic region is 3.2 and $5.1 \%$, respectively. ${ }^{15}$ 
clinical and laboratory characteristics at diagnosis of 228 children and adolescents with AT examined in our Pediatric Endocrine Unit during a 5-year period. Most of the subjects were asymptomatic, the majority were female and pubertal, $6.6 \%$ had another autoimmune disease, $76.3 \%$ had a family history of thyroid disease in a first degree relative and $8.8 \%$ had a family history of autoimmune disease other than AT in a first degree relative. Of the whole group, $57.0 \%$ were euthyroid, $32.9 \%$ had subclinical hypothyroidism, $8.3 \%$ had hypothyroidism and $1.8 \%$ had hyperthyroidism. Goiter was present in $28 \%$ of patients and $14 \%$ had thyroid nodules. Three children $(1.3 \%)$ had a papillary thyroid carcinoma. As expected, a positive correlation between TSH levels and thyroid volume SDS was observed, since TSH is a major determinant of thyroid growth. Children with hypothyroidism were almost one year younger than euthyroid children; the majority of children with hypothyroidism were prepubertal, whereas the majority of euthyroid children were pubertal. Children with hypothyroidism had higher thyroid volume, thyroid volume SDS and prevalence of goiter than euthyroid children and children with subclinical hypothyroidism. Our study has the advantage of assessing a large number of children with AT using thyroid ultrasonography, which is an objective method for estimation of thyroid volume. The limitation of our study was the inability to accurately define antibody titres, because the method of detecting thyroid autoantibodies was changed in our laboratory during the study period. However, assuming as strongly positive thyroid antibodies those 10 times above the normal range (with either method of antibody detection), we have been able to show that hypothyroidism was associated with the presence of strongly positive anti-TPOAb (as previously observed $)^{17}$ and of strongly positive both anti-TPOAb and anti-TgAb.

The most common reasons for referral in our study were investigation of growth (not necessarily abnormal growth), thyroid enlargement and a family history of thyroid disease. It should be clarified, however, that according to the health system in Greece, in contrast to other countries, there is easy access to specialised clinics and most children seen in our Pediatric Endocrine units are self referrals (usually due to parental concerns) and to a lesser extent refer- rals from primary care physicians. In other studies assessing children with AT, the reasons for referral are somewhat different, since tertiary centres accept referrals mostly from primary health centres; the most common reason for referral in these studies being enlargement of the thyroid and symptoms related to thyroid dysfunction. ${ }^{17-20}$ In the majority of our patients in whom AT was diagnosed, clinical symptoms were not present and only a few children were assessed on the basis of strong clinical suspicion. We observed a trend towards an increasing number of children with AT attending our outpatient clinic during the study period; it is not known whether this is due to a progressively increasing prevalence of the disease in Greece or to an increasing awareness on the part of parents and primary care physicians.

In recent years there have been several studies assessing clinical and epidemiological characteristics of children and adolescents with AT (Table 4). In these studies the ethnic background, referral strategies, entry criteria, study design and number of subjects assessed are variable. The children in our study at diagnosis were mostly euthyroid, as were children with AT in an Italian study ${ }^{23}$ and in the high risk (children with type 1 diabetes, Turner syndrome, Down syndrome) asymptomatic group described by DeBoer et al. ${ }^{19}$ However, the prevalence of euthyroidism among children with AT in other studies is lower. ${ }^{17-20,24}$ The prevalence of goiter in our cohort was $28 \%$; DeBoer et al observed a prevalence of $10 \%$ among the high risk asymptomatic group with AT whereas in other groups of mostly symptomatic children with AT the prevalence of goiter varied from 55 to $100 \% .{ }^{17-20,24}$ The low prevalence of goiter in our group could be attributed to the fact that our cohort primarily included asymptomatic euthyroid children. The prevalence of thyroid nodules was $14 \%$ in our patients and $1.3 \%$ had papillary thyroid cancer. Corrias et al found thyroid nodules in $31.5 \%$ of Italian children with AT and 3.0\% were diagnosed as having papillary thyroid cancer. ${ }^{23}$ Although thyroid cancer is an uncommon childhood malignancy with a reported incidence 0.5 to 1.2 per million, our data and those previously reported ${ }^{25}$ suggest that the prevalence of papillary thyroid carcinoma is higher in children with AT, a finding which may have an impact on the management and follow-up of patients with AT. ${ }^{26,27}$ 


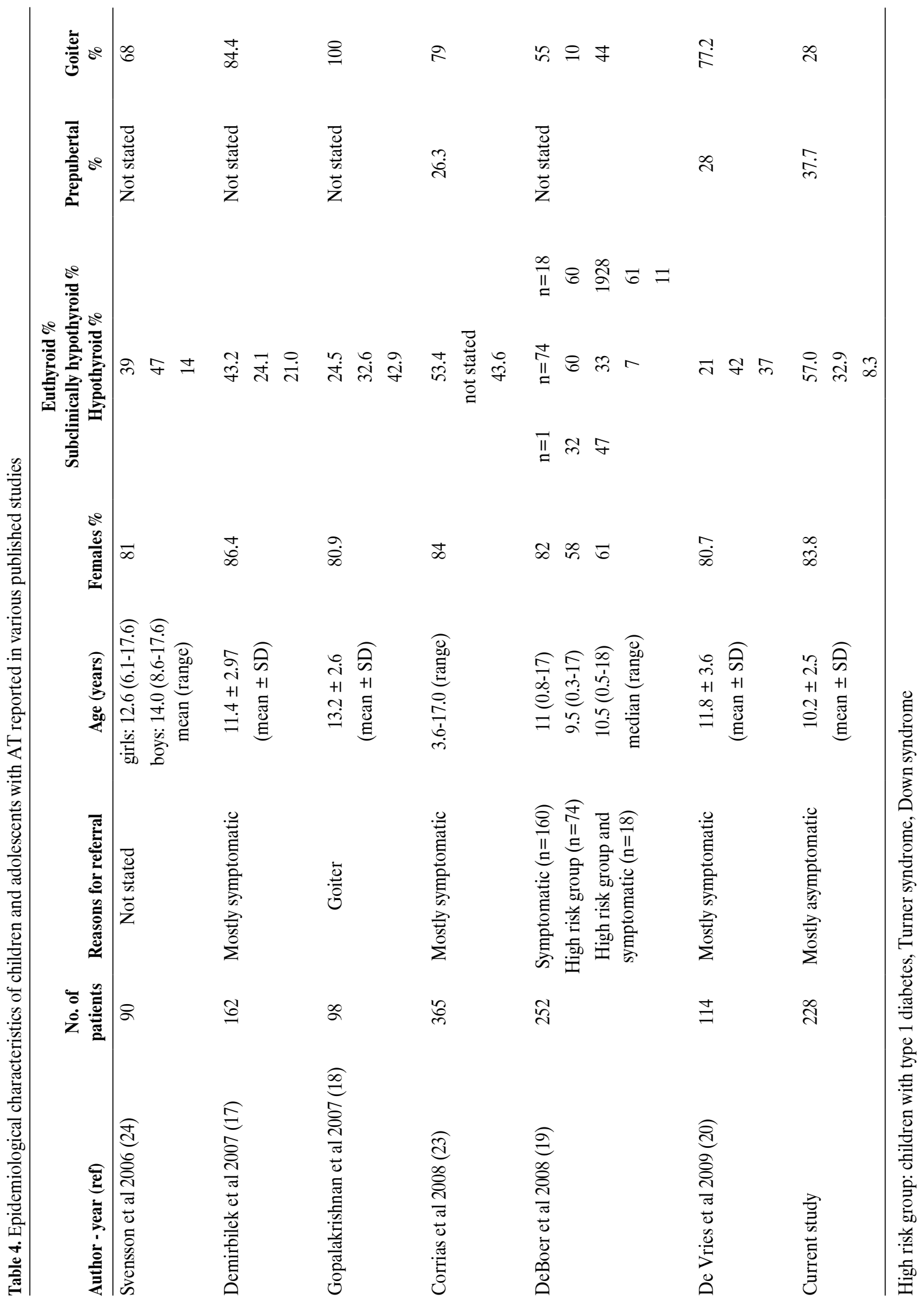


We also observed a significant difference in the prevalence of goiter between subgroups: among the hypothyroid children the prevalence of goiter was a high as $57.9 \%$, whereas it was much lower among the euthyroid children $(22.3 \%)$. The children with hypothyroidism were mostly prepubertal and younger and had higher thyroid volume, thyroid volume SDS and prevalence of goiter than euthyroid children, suggesting that they were at an advanced stage of the disease at an earlier age. De Vries et al found that the prevalence of goiter (detected by palpation) was significantly higher (92\%) in the euthyroid group, compared to the prevalence $(66 \%)$ in the subclinical hypothyroid and the hypothyroid group $(76 \%){ }^{20}$ Svensson et al found a comparable prevalence of goiter among euthyroid, subclinically hypothyroid and hypothyroid children assessed by ultrasound. ${ }^{23}$

Discrepancies between studies may be due to different methods of assessing goiter and thyroid nodules (thyroid ultrasonography is now considered superior for estimating thyroid size to palpation), ${ }^{28}$ differences in the genetic background of the study population, but also to differences in the referral strategies. The referral system in Greece, allowing access to specialised clinics, not on the basis of clinical suspicion by the primary physician care but mainly on parent's concerns, is probably a significant determinant of the characteristics of our study cohort; the majority of children were asymptomatic and only a few $(8.3 \%)$, younger and mostly prepubertal, had overt hypothyroidism, even though the prevalence of overt hypothyroidism increases with age. Probably the children who were hypothyroid at initial recognition of AT had a more severe disease, this also deduced by the higher prevalence of thyroid auto-antibodies in this subgroup.

Similarly to our study, in all previous studies assessing AT in a pediatric population, there is a female preponderance, the prevalence of female gender being approximately $80-86 \%$ in most studies. ${ }^{17,18,20,24}$ The reasons for the increased prevalence of AT and other autoimmune diseases in females has long been recognized but the underlying mechanisms remain unknown. Female hormones, environmental factors and genetic predisposition, including skewing of the $\mathrm{X}$-chromosome inactivation, have been implicated. ${ }^{29,30}$
In conclusion, children and adolescents with AT are mostly asymptomatic at the time of diagnosis, the majority of subjects being female, pubertal and euthyroid. The prevalence of goiter among these children is $28 \%$, of thyroid nodules $14 \%$ and of papillary thyroid cancer $1.3 \%$. Most children with AT (76\%) have a positive family history of thyroid disease. The hypothyroid children of our cohort had higher thyroid volume and higher prevalence of goiter and tend to have higher anti-thyroid antibodies than euthyroid children. Diagnosing AT at an early stage offers the opportunity for a timely intervention. The potential association of AT with papillary thyroid carcinoma is an additional reason for a careful follow-up of patients with AT.

\section{REFERENCES}

1. Dayan CM, Daniels GH, 1996 Chronic autoimmune thyroiditis. N Engl J Med 335: 99-107.

2. Gordin A, Maatela J, Miettinen A, Helenius T, Lamberg BA, 1979 Serum thyrotrophin and circulating thyroglobulin and thyroid microsomal antibodies in a Finnish population. Acta Endocrinol 90: 33-42.

3. Tunbridge WM, Evered DC, Hall R, et al, 1977 The spectrum of thyroid disease in a community: the Whickham survey. Clin Endocrinol (Oxf) 7: 481-493.

4. Barbato MP, 1978 Thyroid autoantibodies in an Australian community. Med J. Aust 2: 511-512.

5. Spencer CA, Hollowell JG, Kazarosyan M, Braverman LE, 2007 National Health and Nutrition Examination Survey III thyroid-stimulating hormone (TSH)-thyroperoxidase antibody relationships demonstrate that TSH upper reference limits may be skewed by occult thyroid dysfunction. J Clin Endocrinol Metab 92: 4236-4240.

6. Gopalakrishnan S, Marwaha RK, 2007 Juvenile autoimmune thyroiditis. J Pediatr Endocrinol Metab 20: 961-970.

7. Rallison ML, Dobyns BM, Meikle AW, Bishop M, Lyon JL, Stevens W, 1991 Natural history of thyroid abnormalities: prevalence, incidence, and regression of thyroid diseases in adolescents and young adults. Am J Med 91: 363-370.

8. Leboeuf G, Ducharme JR, 1966 Thyroiditis in children. Diagnosis and management. Pediatr Clin North Am 13: 19-42.

9. Jaruratanasirikul S, Leethanaporn K, Khuntigij P, Sriplung H, 2001 The clinical course of Hashimoto's thryoiditis in children and adolescents: 6 years longitudinal follow-up. J Pediatr Endocrinol Metab 14: 177-184.

10. Mäenpää J, Raatikka M, Räsänen J, Taskinen E, Wager O, 1985 Natural course of juvenile autoimmune thyroiditis. J Pediatr 107: 898-904.

11. Zois C, Stavrou I, Svarna E, Seferiadis K, Tsatsoulis 
A, 2006 Natural course of autoimmune thyroiditis after elimination of iodine deficiency in northwestern Greece. Thyroid 16: 289-293.

12. Wang SY, Tung YC, Tsai WY, Lee JS, Hsiao PH, 2006 Long-term outcome of hormonal status in Taiwanese children with Hashimoto's thyroiditis. Eur J Pediatr 165: 481-483.

13. Radetti G, Gottardi E, Bona G, et al, 2006 The natural history of euthyroid Hashimoto's thyroiditis in children. J Pediatr 149: 827-832.

14. Zois C, Stavrou I, Kalogera C, et al, 2003 High prevalence of autoimmune thyroiditis in schoolchildren after elimination of iodine deficiency in northwestern Greece. Thyroid 13: 485-489.

15. Kaloumenou I, Alevizaki M, Ladopoulos C, et al, 2007 Thyroid volume and echostructure in schoolchildren living in an iodine-replete area: relation to age, pubertal stage, and body mass index. Thyroid 17: 875-881.

16. Kaloumenou I, Mastorakos G, Alevizaki M, et al, 2008 Thyroid autoimmunity in schoolchildren in an area with long-standing iodine sufficiency: correlation with gender, pubertal stage, and maternal thyroid autoimmunity. Thyroid 18: 747-754.

17. Demirbilek H, Kandemir N, Gonc EN, Ozon A, Alikasifoglu A, Yordam N, 2007 Hashimoto's thyroiditis in children and adolescents: a retrospective study on clinical, epidemiological and laboratory properties of the disease. J Pediatr Endocrinol Metab 20: 1199-1205.

18. Gopalakrishnan S, Chugh PK, Chhillar M, Ambardar VK, Sahoo M, Sankar R, 2008 Goitrous autoimmune thyroiditis in a pediatric population: a longitudinal study. Pediatrics 122: e670-674.

19. DeBoer MD, LaFranchi S, 2008 Differential presentation for children with autoimmune thyroiditis discovered because of symptom development or screening. J Pediatr Endocrinol Metab 21: 753-761.

20. de Vries L, Bulvik S, Phillip M 2009 Chronic autoimmune thyroiditis in children and adolescents: at presentation and during long-term follow-up. Arch Dis Child 94: 33-37.
21. Brunn J, Block U, Ruf G, Bos I, Kunze WP, Scriba PC, 1981 Volumetric analysis of thyroid lobes by real-time ultrasound (author's transl). Dtsch Med Wochenschr 106: 1338-1340.

22. Set PA, Oleszczuk-Raschke K, von Lengerke JH, Brämswig J, 1996 Sonographic features of Hashimoto thyroiditis in childhood. Clin Radiol 51: 167-169.

23. Corrias A, Cassio A, Weber G, et al, 2008 Thyroid nodules and cancer in children and adolescents affected by autoimmune thyroiditis. Arch Pediatr Adolesc Med 162: 526-531.

24. Svensson J, Ericsson UB, Nilsson P, et al, 2006 Levothyroxine treatment reduces thyroid size in children and adolescents with chronic autoimmune thyroiditis. J Clin Endocrinol Metab 91: 1729-1734.

25. Steliarova-Foucher E, Stiller CA, Pukkala E, Lacour B, Plesko I, Parkin DM, 2006 Thyroid cancer incidence and survival among European children and adolescents (1978-1997): report from the Automated Childhood Cancer Information System project. Eur J Cancer 42: 2150-2169.

26. Feldt-Rasmussen U, Rasmussen AK, 2010 Autoimmunity in differentiated thyroid cancer: significance and related clinical problems. Hormones (Athens) 9: 109-117.

27. Mazokopakis EE, Tzortzinis AA, Dalieraki-Ott EI, et al, 2010 Coexistence of Hashimoto's thyroiditis with papillary thyroid carcinoma. A retrospective study. Hormones (Athens) 9: 312-317.

28. Lisböa HR, Gross JL, Orsolin A, Fuchs S, 1996 Clinical examination is not an accurate method of defining the presence of goiter in schoolchildren. Clin Endocrinol (Oxf) 45: 471-475.

29. Whitacre CC, 2001 Sex differences in autoimmune disease. Nat Immunol 2: 777-780.

30. Brix TH, Knudsen GP, Kristiansen M, Kyvik KO, Orstavik KH, Hegedüs L, 2005 High frequency of skewed $\mathrm{X}$-chromosome inactivation in females with autoimmune thyroid disease: a possible explanation for the female predisposition to thyroid autoimmunity. J Clin Endocrinol Metab 90: 5949-5953. 